\title{
CrystEngComm
}

Check for updates

Cite this: CrystEngComm, 2020, 22, 5854

Received 11th June 2020,

Accepted 11th August 2020

DOI: $10.1039 /$ d0ce00847h

rsc.li/crystengcomm

\section{Counter-ion influence on the mechanism of HMTA-mediated ZnO formation $\dagger$}

\author{
Mark M. J. van Rijt, (D) Bernette M. Oosterlaken, (D) Rick R. M. Joosten, \\ Levina E. A. Wijkhuijs, (iD Paul H. H. Bomans, \\ Heiner Friedrich iD and Gijsbertus de With iD *
}

\begin{abstract}
Crystalline materials are often formed via transient phases. Here we focus on $\mathrm{ZnO}$ as a widely used and investigated material for technological applications. Although the literature for the wet chemical synthesis of $\mathrm{ZnO}$ is extensive, its formation pathway using these strategies has gained limited attention so far and is poorly understood. To gain insight into these pathways, a HMTA-mediated ZnO synthesis protocol with a variety of zinc salts was employed using in situ $\mathrm{pH}$ measurements combined with discrete cryoTEM and SEM sampling studies, in addition to more typical PXRD and SEM product analysis. These results indicate a significant counter-ion effect on the reaction product. Using acetate, nitrate, chloride and sulphate as counter-ions all result first in the formation of a layered zinc hydroxy salt (LZHS), the exact composition of which depends on the counter-ion. Rather stable LZHSs are formed using chloride and sulphate, preventing the eventual formation of $\mathrm{ZnO}$. Only acetate and nitrate result in the formation of $\mathrm{ZnO}$. For acetate, $\mathrm{ZnO}$ is preferably grown in-dispersion, while for nitrate it is formed on exposed solid interfaces to the reaction medium (on-surfaces). For the latter the nucleation of its LZHS precursor requires an additional incubation time, resulting in heterogeneous nucleation instead.
\end{abstract}

\section{Introduction}

Non-classical crystallization pathways, i.e. the multi-step progression from transient phases $^{1}$ have been observed for multiple minerals including magnetite, ${ }^{2}$ hydroxy apatite ${ }^{3}$ and calcium carbonate. ${ }^{4}$ Similarly, for the synthesis of zinc oxide (ZnO) under aqueous conditions, it is generally accepted that either zinc hydroxide ${ }^{5-8}$ or layered zinc hydroxy salts (LZHS) ${ }^{9-13}$ are formed as a transient phase.

A common strategy for the formation of high quality $\mathrm{ZnO}$ uses the gradual thermal decomposition of hexamethylenetetramine (HMTA) into ammonia and formaldehyde, where after the ammonia reacts with water resulting in the formation of hydroxide. The released hydroxide is subsequently consumed resulting in the formation of $\mathrm{ZnO}$ after several hours at temperatures above $60{ }^{\circ} \mathrm{C}^{9,10,14,15}$ The thermal decomposition rate of HMTA increases with the concentration of protons in the system,

Laboratory of Physical Chemistry, Center for Multiscale Electron Microscopy, Department of Chemical Engineering and Chemistry, Eindhoven University of Technology, P. O. Box 513, 5600 MB Eindhoven, The Netherlands.

E-mail: G.deWith@tue.nl

$\dagger$ Electronic supplementary information (ESI) available: Experimental section, supporting discussion and figures. See DOI: 10.1039/d0ce00847h making the release of hydroxide in the system $\mathrm{pH}$ dependent. $^{16}$ Several $e x$ situ studies on the mechanism of $\mathrm{ZnO}$ formation have been conducted using both zinc acetate $^{9,10,13,14}$ and zinc nitrate ${ }^{10,17-20}$ as a zinc source. For these reactions either layered basic zinc acetate (LBZA, $\left.\mathrm{Zn}_{5}(\mathrm{OH})_{8}\left(\mathrm{CH}_{3} \mathrm{COO}\right)_{2} \cdot 2 \mathrm{H}_{2} \mathrm{O}\right)$ or layered basic zinc nitrate (LBZN, $\left.\mathrm{Zn}_{5}(\mathrm{OH})_{8}\left(\mathrm{NO}_{3}\right)_{2} \cdot 2 \mathrm{H}_{2} \mathrm{O}\right)$ have been observed in the early reaction stages, suggesting they are transient species. It has been postulated by Jang et al. ${ }^{13}$ that these LZHS act as a seeding template for $\mathrm{ZnO}$ dumbbell structures that are frequently formed in dispersion. In situ studies have been performed including LPTEM $^{14,21}$ and STXM ${ }^{22}$ focussing on the growth stage, and XANES, ${ }^{7}$ showing the initial formation of $\left[\mathrm{Zn}\left(\mathrm{OH}_{6}\right)\right]^{2+}$ instead of LZHS.

The formation of ZnO using HMTA is not limited to the use of zinc acetate or zinc nitrate, as other zinc salts such as zinc $N$-dodecyl- $N, N$-dimethylammonioacetic bromide, ${ }^{11}$ zinc formate, ${ }^{5}$ zinc chloride ${ }^{23,24}$ and zinc sulphate, ${ }^{25}$ have been successfully used. However, only a few papers used similar reaction conditions for different zinc salts to investigate the influence of the counter-ion ${ }^{5,23}$ so that a general understanding of the counter-ion role during the $\mathrm{ZnO}$ formation is currently lacking. To date counter-ions are mainly described as capping agents, e.g. resulting in the formation of hexagonal platelets when using zinc sulphate, in contrast to the typically formed hexagonal rods for $>4 \mathrm{~nm}$ 
ZnO crystals. $^{25-27}$ Given the observation of counter-ion specific intermediates, it is highly likely that the counter-ion will have a significant influence on the reaction.

Here we investigate the influence of various zinc counterions on the formation of $\mathrm{ZnO}$ using a mild HMTA-based reaction strategy. We show that the selection of the counterion has a strong influence on the process and the final reaction product. Furthermore, for the formation of $\mathrm{ZnO}$ the counter-ion, dependent on reaction conditions, can direct the growth of $\mathrm{ZnO}$ in-dispersion or on-surfaces. Finally, in situ pH measurements are combined with discrete cryoTEM and SEM sampling to gain insight in the underlying formation mechanism of $\mathrm{ZnO}$.

\section{Results and discussion}

\section{Counter-ion influence on the reaction product}

The influence of zinc counter-ions on $\mathrm{ZnO}$ crystallization was investigated using a protocol similar to Ou et $a .^{28}$ In brief, by reacting $50 \mathrm{mM}$ zinc salt and $25 \mathrm{mM}$ hexamine (HMTA) in pure water at $80^{\circ} \mathrm{C}$ for $6 \mathrm{~h}$ at ambient pressure, see $\mathrm{ESI} \dagger$ section 1. Four different zinc salts were investigated: zinc acetate $\left(\mathrm{ZnAc}_{2}\right)$, chloride $\left(\mathrm{ZnCl}_{2}\right)$, nitrate $\left(\mathrm{Zn}\left(\mathrm{NO}_{3}\right)_{2}\right)$ and sulphate $\left(\mathrm{ZnSO}_{4}\right)$. In all cases a white precipitate was obtained after the reaction (Fig. S1 $\dagger$ ). For $\mathrm{Zn}\left(\mathrm{NO}_{3}\right)_{2}$ the precipitate formed dominantly on the flask wall and on the $\mathrm{pH}$ probe, resulting in a clear solution. In contrast, for the other three salts most (all in the case of $\mathrm{ZnSO}_{4}$ ) of the precipitate was formed in dispersion.

For all zinc salts, in situ $\mathrm{pH}$ measurements (Fig. 1a) showed an initial rapid decrease in $\mathrm{pH}$ with increasing reaction temperature. The observed $\mathrm{pH}$ minima show a counter-ion dependence with the highest $\mathrm{pH}$ minima being observed for $\mathrm{ZnAc}_{2}$ (5.8) followed by $\mathrm{Zn}\left(\mathrm{NO}_{3}\right)_{2}$ (5.6), $\mathrm{ZnCl}_{2}$ (5.5) and $\mathrm{ZnSO}_{4}$ (5.4). Following the initial drop in $\mathrm{pH}$, a stabilization or gradual increase in $\mathrm{pH}$ is observed over time. Only when $\mathrm{ZnAc}_{2}$ is used this constant $\mathrm{pH}$ trend is interrupted by a distinct second drop in $\mathrm{pH}$ of $0.1-0.2 \mathrm{pH}$ points. This drop is typically observed after $2 \mathrm{~h}$ reaction time $(\mathrm{ESI} \dagger$ section 3). After $6 \mathrm{~h}$ reaction time the $\mathrm{pH}$ of the reaction solution has raised to 5.8 for $\mathrm{ZnAc}_{2}$, 5.7 for $\mathrm{ZnCl}_{2}$ and 5.6 for both $\mathrm{Zn}\left(\mathrm{NO}_{3}\right)_{2}$ and $\mathrm{ZnSO}_{4}$.

The morphologies and crystallinity of the purified reaction products were investigated using SEM (Fig. 1b-e) and pXRD (Fig. 1f). For both $\mathrm{ZnAc}_{2}$ and $\mathrm{Zn}\left(\mathrm{NO}_{3}\right)_{2}$ hexagonal pillarshaped wurtzite $\mathrm{ZnO}$ crystals were formed. Use of $\mathrm{ZnAc}_{2}$ typically resulted in a dumbbell structure. The reactions using $\mathrm{ZnCl}_{2}$ and $\mathrm{ZnSO}_{4}$ resulted in the formation of frequently hexagonally faceted plate-shaped crystals of $\mathrm{Zn}_{5}(\mathrm{OH})_{8} \mathrm{Cl}_{2} \cdot \mathrm{H}_{2} \mathrm{O}$ (LBZC) and ${ }^{29} \mathrm{Zn}_{4}(\mathrm{OH})_{6} \mathrm{SO}_{4} \cdot 4 \mathrm{H}_{2} \mathrm{O}$ (LBZS), respectively. ${ }^{30}$ The plate-shaped crystals are not dissimilar to crystals observed by Govender et al. ${ }^{5}$ Thus for $\mathrm{ZnCl}_{2}$ and $\mathrm{ZnSO}_{4}$ no evidence of $\mathrm{ZnO}$ formation was observed using pXRD and this was supported by the observation of only one morphology by SEM. When comparing the reaction $\mathrm{pH}$ profiles, it can be observed that for $\mathrm{ZnCl}_{2}$ and $\mathrm{ZnSO}_{4}$ the
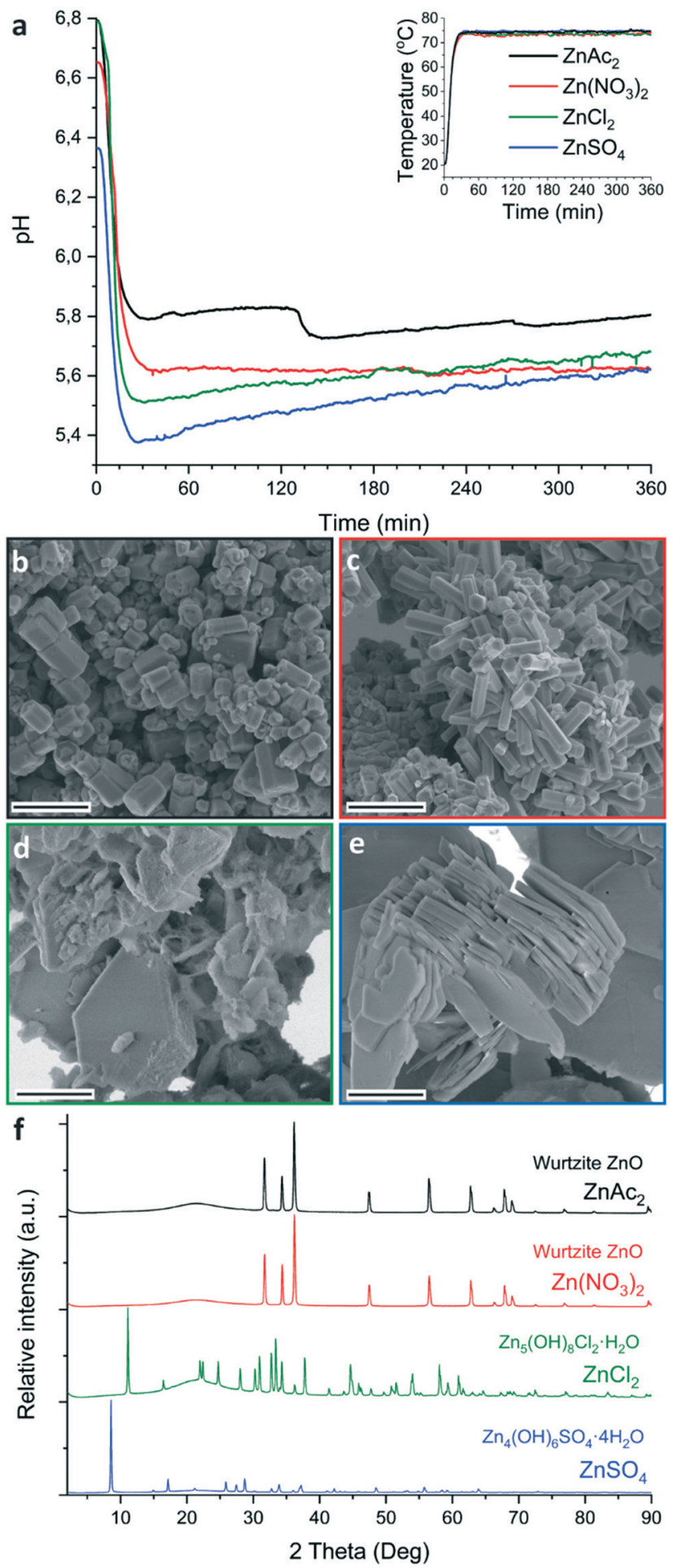

Fig. 1 HMTA-mediated synthesis of $\mathrm{ZnO}$ showing $\mathrm{pH}$ (a) and temperature (inset) profiles, combined with SEM images (b-e) and pXRD data ( $f$ ) of the reaction products when using $\mathrm{ZnAc}_{2}$ (b, black), $\mathrm{Zn}\left(\mathrm{NO}_{3}\right)_{2}$ (c, red), $\mathrm{ZnCl}_{2}$ (d, green) and $\mathrm{ZnSO}_{4}$ (e, blue). SEM scales equal $2 \mu \mathrm{m}$. pXRD data is normalized on the highest intensity signal and the broad pXRD signal visible at about $20^{\circ}$ is from the substrate.

reaction $\mathrm{pH}$ is slightly lower than when using the $\mathrm{ZnO}$ forming zinc salts. Furthermore, when $\mathrm{ZnO}$ pillars formed from $\mathrm{ZnAc}_{2}$ and $\mathrm{Zn}\left(\mathrm{NO}_{3}\right)_{2}$ were left in the reaction solution 
for over $24 \mathrm{~h}$, they became hollow (Fig. S2 $\dagger$ ). This is indicative of $\mathrm{pH}$-induced etching due to prolonged exposure to the low $\mathrm{pH}$ reaction solution at RT after synthesis. ${ }^{31}$ This suggests that the reaction $\mathrm{pH}$ when using $\mathrm{ZnAc}_{2}$ and $\mathrm{Zn}\left(\mathrm{NO}_{3}\right)_{2}$ is close to the $\mathrm{pH}$ stability limit of $\mathrm{ZnO}$. In an attempted to raise the reaction $\mathrm{pH}$, base $(0.1 \mathrm{M}$ ammonia) was added dropwise to the $\mathrm{ZnSO}_{4}$ reaction. This led to the formation of a white precipitate at RT without resulting in an increase in $\mathrm{pH}$. After performing the reaction, pXRD showed the formation of a mixture of zinc hydroxy sulphate salts (Fig. S3†). As an alternative to raise the reaction $\mathrm{pH}$, the reaction temperature was lowered for both $\mathrm{ZnCl}_{2}$ and $\mathrm{ZnSO}_{4}$. This increased the observed minima in reaction $\mathrm{pH}$ to 5.7 and 5.8, respectively (Fig. S4a†). After purification pXRD analysis still showed the dominant formation of LBZC and LBZS without any evidence for $\mathrm{ZnO}$ formation (Fig. S4b†). This indicates that the reaction $\mathrm{pH}$ is not the main cause for the formation of LZHS instead of $\mathrm{ZnO}$ when using $\mathrm{ZnCl}_{2}$ or $\mathrm{ZnSO}_{4}$.

\section{Mechanism of HMTA-mediated $\mathrm{ZnO}$ formation in dispersion}

To understand how $\mathrm{ZnAc}_{2}$ transforms in dispersion into $\mathrm{ZnO}$, discrete cryoTEM sampling studies were conducted (Fig. 2). Given that the features in the $\mathrm{pH}$ curve tend to shift in time between experiments due to the stochastic nature of nucleation and crystallization (ESI $\dagger$ section 3), cryoTEM sampling points are chosen and indicated based on curve features rather than absolute time points (Fig. 2aI). Dissolving $\mathrm{ZnAc}_{2}$ and HMTA in water yielded a transparent solution. CryoTEM prior to the start of the reaction showed the presence of $\sim 200 \mathrm{~nm}$ sized sheets (Fig. 2b). These sheets tend to orient with the TEM grid and are predominantly observed in clusters. Low dose selected area electron diffraction (LDSAED) of such clusters showed the presence of two diffuse rings originating from vitreous water and three faint but sharp rings, which include stronger diffraction spots, matching the (010), (120) and (020) spacing of either wurtzite ZnO or LBZA (Fig. 3 and S5†). When the temperature is gradually increased to initiate the reaction, cryoTEM imaging shows that the lateral size of the sheets increases significantly (Fig. 2c) concomitant with a decrease in $\mathrm{pH}$ from 6.8 to 5.8. LDSAED shows that these sheets are single crystals (Fig. S5b and $\mathrm{e}^{\dagger}$ ), in agreement with previous observations on LBZA, ${ }^{32,33}$ with a preferred growth in the [010] direction. The maxima of the most prominent diffraction signals match with those of the $\sim 200 \mathrm{~nm}$ sheets (Fig. 3). This clearly shows that LBZA is formed when dissolving the reactants prior to the start of the reaction at RT. Upon temperature increase, which initiates the reaction, growth of LBZA sheets accelerates resulting in increased hydroxide consumption and a concomitant decrease in $\mathrm{pH}$.

The initial $\mathrm{pH}$ drop lasts for about $30 \mathrm{~min}$ when the temperature has reached approximately $75{ }^{\circ} \mathrm{C}$. Thermal decomposition of HMTA, which starts at $50{ }^{\circ} \mathrm{C}$, does not impact the slope of the $\mathrm{pH}$ drop. This suggests that the hydroxide, released by HMTA decomposition - ammonia formation - is immediately consumed by the formation of LBZA. Subsequently, the pH stabilizes close to 5.8 with only a slight increase being observed in time. At the beginning of the first $\mathrm{pH}$ plateau, LBZA sheets with a width of over $1 \mu \mathrm{m}$ in some cases (Fig. 2d) can be regularly observed by cryoTEM. It should be noted that even at this stage small nanometersized sheets, like those observed at RT, are still present.

CryoTEM imaging at $60 \mathrm{~min}$ reaction time shows that the LBZA sheets have even further increased in size, with some having a width of more than $5 \mu \mathrm{m}$ (Fig. 2e and $\mathrm{f}$ and S6†). From this timepoint onward, ZnO pillars can be observed in dispersion using cryoTEM (Fig. 2aII), suggesting that the ZnO nucleation takes place after formation of large LBZA sheets. Given above findings and the similar lattice spacings of wurtzite $\mathrm{ZnO}$ and LBZA, it seems reasonable to assume that LBZA plays a role in the formation of ZnO. However, cryoTEM provides no direct evidence for this hypothesis. Furthermore, it is striking that the formation of $\mathrm{ZnO}$ crystals does not rapidly consume all available LBZA, in fact, it seems that LBZA sheets continue to increase in size during the nucleation and initial growth of $\mathrm{ZnO}$ pillars.

The first $\mathrm{pH}$ plateau ends with a spontaneous second decrease in $\mathrm{pH}$ (Fig. 2aIII). Under typical reaction conditions this $\mathrm{pH}$ drop occurs after about $2 \mathrm{~h}$ reaction time. Surprisingly, during cryoTEM sampling experiments this $\mathrm{pH}$ drop occurred earlier (as early as 75 min reaction time), and in several cases directly after sampling (ESI† section 3) as will be discussed in more detail later. The spontaneous decrease in $\mathrm{pH}$, which consequently will again accelerate the proton catalyzed decomposition of HMTA and subsequent release of hydroxide, ${ }^{34}$ can only be explained by a spontaneous increase in the consumption of hydroxide by the reaction.

After the onset of this second $\mathrm{pH}$ drop no rectangular shaped LBZA crystals were observed by cryoTEM (Fig. $2 \mathrm{~g}$ and 4), indicating that the $\mathrm{pH}$ drop corresponded with a rapid decrease in the number of LBZA crystals present. Simultaneously, the size of $\mathrm{ZnO}$ crystals increased from $470 \pm$ $330 \mathrm{~nm}$ to $660 \pm 380 \mathrm{~nm}$ in length during the first 9 minutes of the pH drop (Fig. S7 and S8 $\dagger$ ), while the aspect ratio stayed almost constant at 2.4 vs. 2.3, respectively. Simplifying the shape of $\mathrm{ZnO}$ crystals as cylinders, this corresponds to a $\mathrm{ZnO}$ volume increase of 2.8 times. At the end of the second $\mathrm{pH}$ drop (27 $\mathrm{min}$ in the process), a $\mathrm{ZnO}$ rod length of $650 \pm 250$ $\mathrm{nm}$ is measured with an aspect ratio of 2.2. This shows that $\mathrm{ZnO}$ crystal growth is most pronounced at the start of the second $\mathrm{pH}$ drop. Given that LBZA contains hydroxide moieties, spontaneous dissolution of LBZA would result in a strong $\mathrm{pH}$ increase. The rapid increase in $\mathrm{ZnO}$ size and the corresponding decrease in $\mathrm{pH}$ indicate that the LBZA is not gradually dissolved, but instead rapidly consumed by accelerated $\mathrm{ZnO}$ crystal growth.

Although $\mathrm{ZnO}$ has become the main phase after the onset of the second $\mathrm{pH}$ drop, other transient phases are present. Throughout the $\mathrm{pH}$ decrease a variety of coexisting phase are observed including folded sheets (Fig. 4a) and high contrast regions, that appear to be particulated on a higher 
a
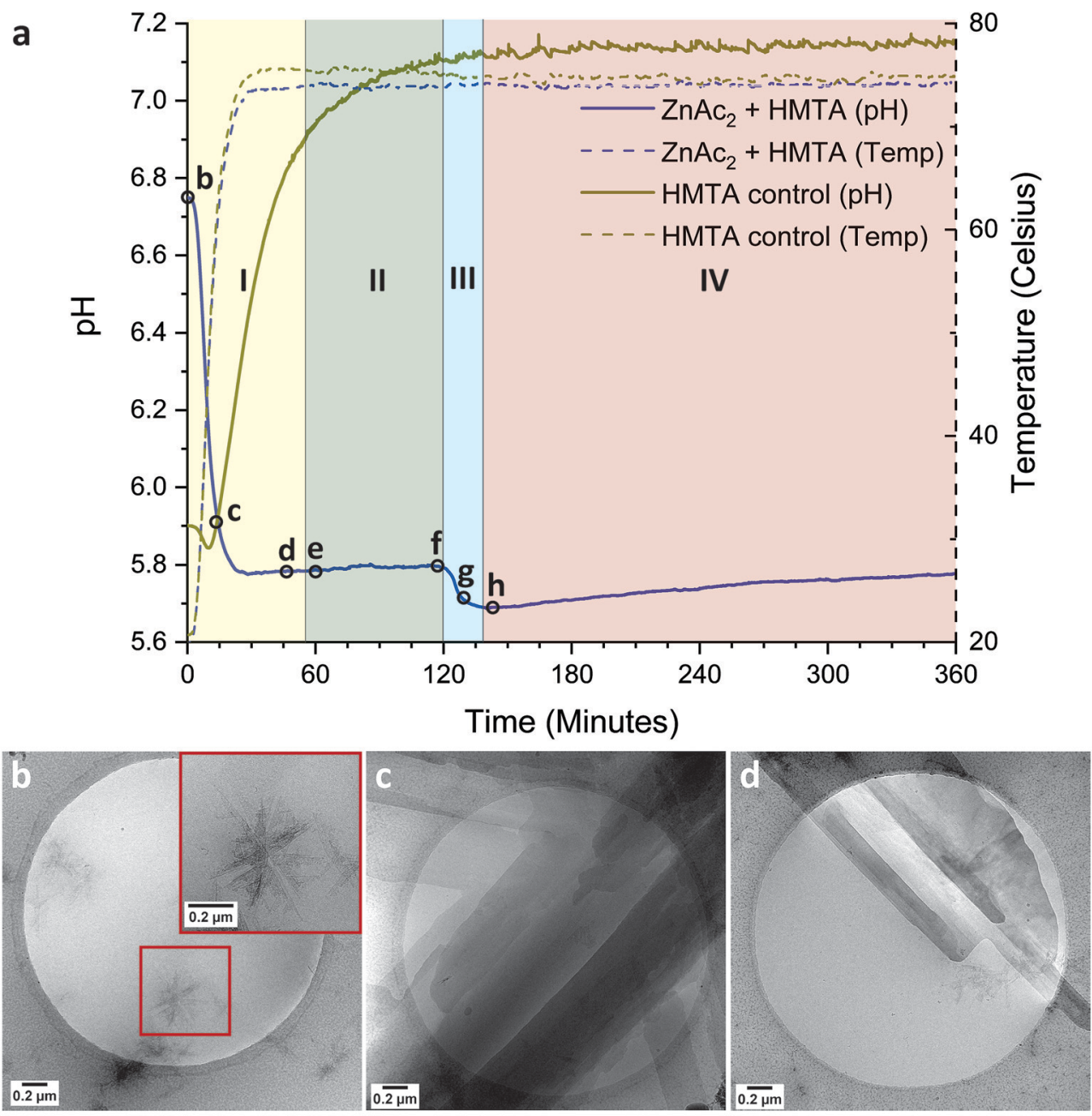
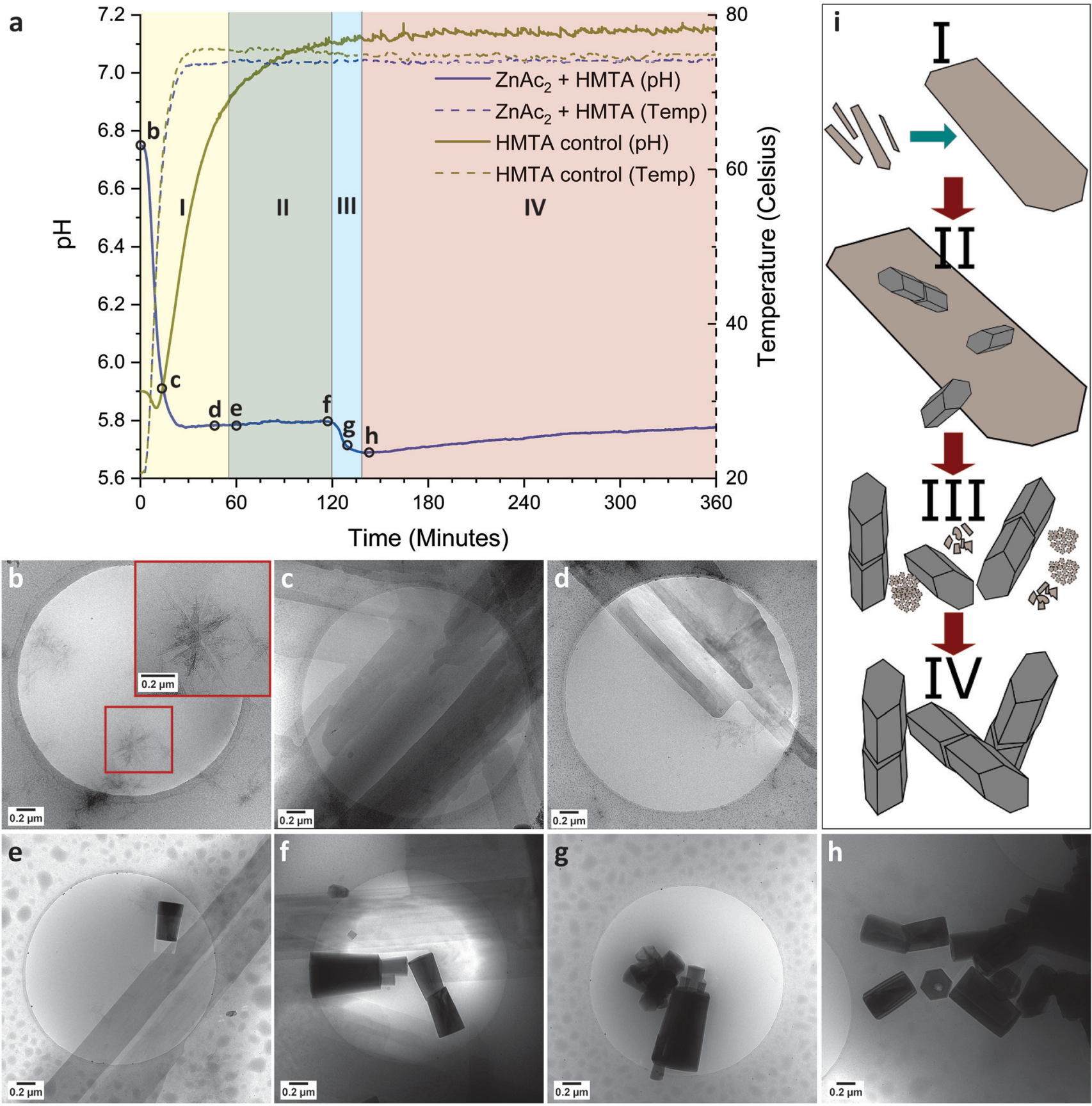

Fig. $2 \mathrm{pH}$ (continuous) and temperature (dashed) profiles of the $\mathrm{ZnAc}_{2} / \mathrm{HMTA}$ reaction (blue) versus HMTA decomposition (gold) (a). CryoTEM images (b-h) obtained from discrete sampling, selected points are indicated in the $\mathrm{pH}$ curve. Sketch of products observed by cryoTEM at different time points (i) showing only LBZA sheets (region I, a), nucleation of ZnO in presence of LBZA (region II, a), fast disintegration of LBZA (region III, a) and of the final $\mathrm{ZnO}$ reaction product (region IV, a).

magnification (Fig. 4b). LDSAED of both phases matches with the earlier observed LBZA spacings (Fig. 3). Furthermore, clusters of amorphous nanometer-sized particles are also observed at multiple time points (Fig. 3 and $4 \mathrm{c}$ and d).

After the end of the second $\mathrm{pH}$ drop a gradual increase in $\mathrm{pH}$ is observed. For this stage cryoTEM shows that ZnO is the dominant species present (Fig. 2h). This matches pXRD data obtained after $6 \mathrm{~h}$ reaction time (Fig. 1f). During this time period, base will still be released by HMTA decomposition, whereas the $\mathrm{pH}$ only gradually increases from 5.8 to 5.7 (Fig. 2aIV). The remainder of the released base is likely consumed by the growth of the $\mathrm{ZnO}$ crystals present.

By using cryoTEM sampling only a fraction of the reaction volume can be investigated. Due to this fact, only local information is obtained at a specific time point. Therefore, to confidently track the evolution in sample composition accurately in a relatively small timeframe it is imperative that the transition process occurs uniformly throughout the 


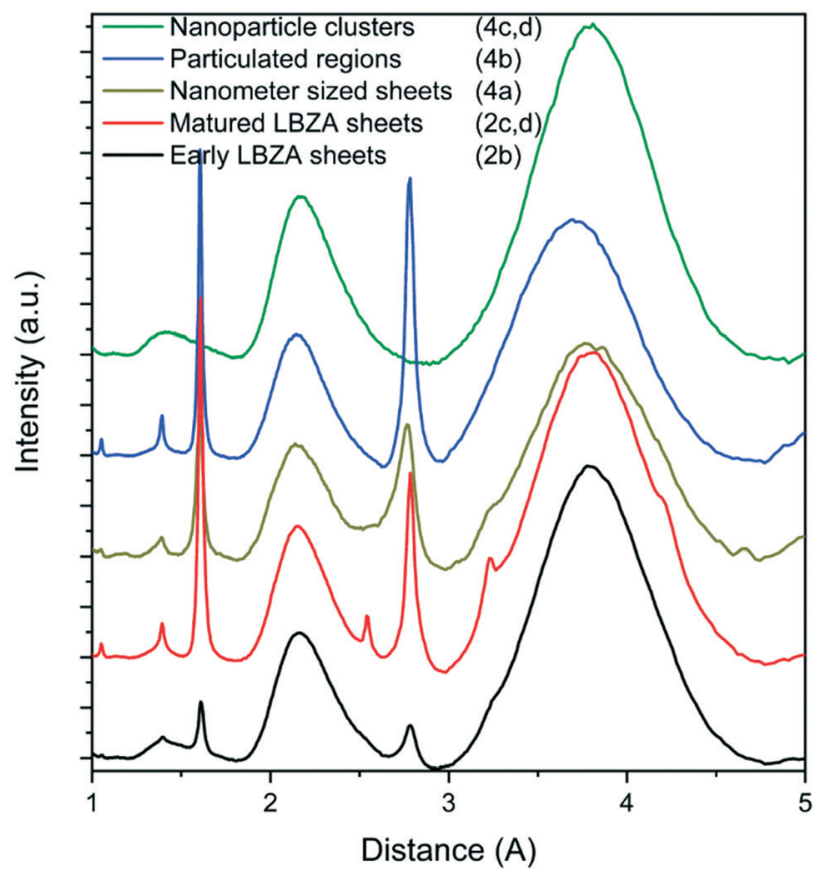

Fig. 3 Radial averaged LDSAED data at different time points showing the initially observed small $\sim 200 \mathrm{~nm}$ LBZA (black), the large "matured" LBZA sheets (red) and species observed after the second $\mathrm{pH}$ drop; nanometer-sized sheets (gold), high-contrast particulated regions (blue), and amorphous nanoparticle clusters (green). The full LDSAED patterns are shown in Fig. S5.†
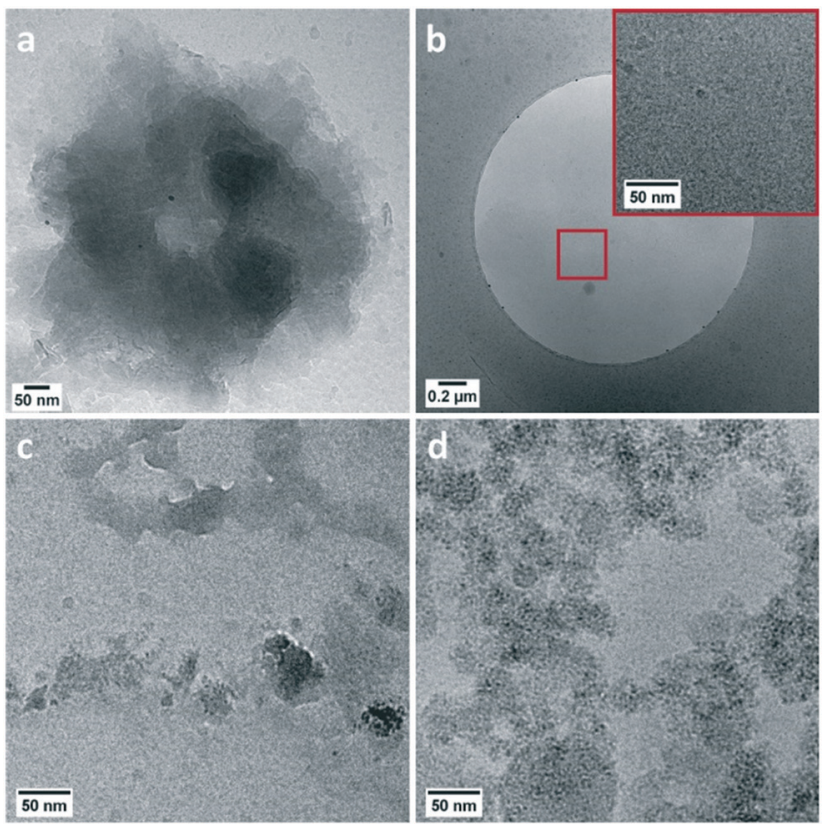

Fig. 4 CryoTEM images of phases observed throughout the second drop in $\mathrm{pH}$ including: folded sheets (a), high-contrast particulated regions (b) and clusters of nanoparticles (c and d).

reaction. Given that for a fast and spontaneous disintegration process a uniform transition is unlikely, it is impossible to confidently chart the disintegration of the LBZA using cryoTEM sampling. This explains the observation of the coexisting transient phases. In fact, one of the sampling points taken close to the end of the second $\mathrm{pH}$ drop, shows the dominant presence of nanometer-sized particle clusters (ESI $\dagger$ section 3, Fig. 4d) which could correspond with a relative early stage of the disintegration process. These clusters are accompanied by small highly particulated sheets, which possibly correspond to the transition of LBZA into this particle phase. If the LBZA sheets would disintegrate into nanometer-sized particles, this could partially explain the spontaneous rapid decomposition of the species. These particles would be rapidly consumed by present crystals in dispersion, resulting in a rapid size increase for both species.

This leaves the question why the LBZA sheets would spontaneously and rapidly start to disintegrate and how this is accelerated by cryoTEM sampling experiments. The most probable reason is mechanical breaking of the LBZA sheets. LBZA sheets grow throughout the reaction and it is known that crystalline materials are more prone to brittle fracture with increasing size due to the occurrence of crystal defects. ${ }^{35,36}$ When the crystal size surpasses this critical size, brittle fracture will occur due to stress exposure, resulting in shattering of the LBZA sheets. The resulting disintegration of some LBZA sheets will feed and accelerate the growth of other LBZA sheets and ZnO crystals in dispersion. These expanded LBZA sheets will also surpass the critical size and disintegrate, effectively resulting in a rapid autocatalytic collapse of the entire LBZA phase. In contrast, the ZnO crystals grown remain stable, resulting in the formation of a pure $\mathrm{ZnO}$ phase as observed by $\mathrm{pH}$ measurements and cryoTEM sampling. Given that growth rates will be similar for every reaction, the onset of this autocatalytic fracturing can be expected to occur at about the same reaction time, matching observations. When performing cryoTEM sampling, additional strain is added to the system, fracturing some LBZA sheets and expediting the process.

\section{The influence of layered hydroxy salts}

Similar to the use of $\mathrm{ZnAc}_{2}$, the use of $\mathrm{Zn}\left(\mathrm{NO}_{3}\right)_{2}$ resulted in the formation of $\mathrm{ZnO}$. However, in contrast to the other zinc salts used, the $\mathrm{Zn}\left(\mathrm{NO}_{3}\right)_{2}$ reaction product is predominantly formed on solid interfaces submerged in the reaction solution (on-surface growth) e.g. reaction flask and $\mathrm{pH}$ probe. CryoTEM sampling was used to investigate the particles formed in dispersion at both 15 and $30 \mathrm{~min}$ reaction time. Particles were only incidentally observed in dispersion (Fig. $\mathrm{S} 9 \dagger)$, suggesting that during the early reaction stages most of the hydroxide is consumed by the formation of either soluble zinc hydroxide or on-surface crystal growth.

To investigate if on-surface crystal growth occurs during the early stages, SEM was performed on cleaned glass plates (without a seed layer) submerged for a specific time in the reaction medium (Fig. 5). After $15 \mathrm{~min}$ reaction time micrometer-sized crystals were observed on the glass surface 

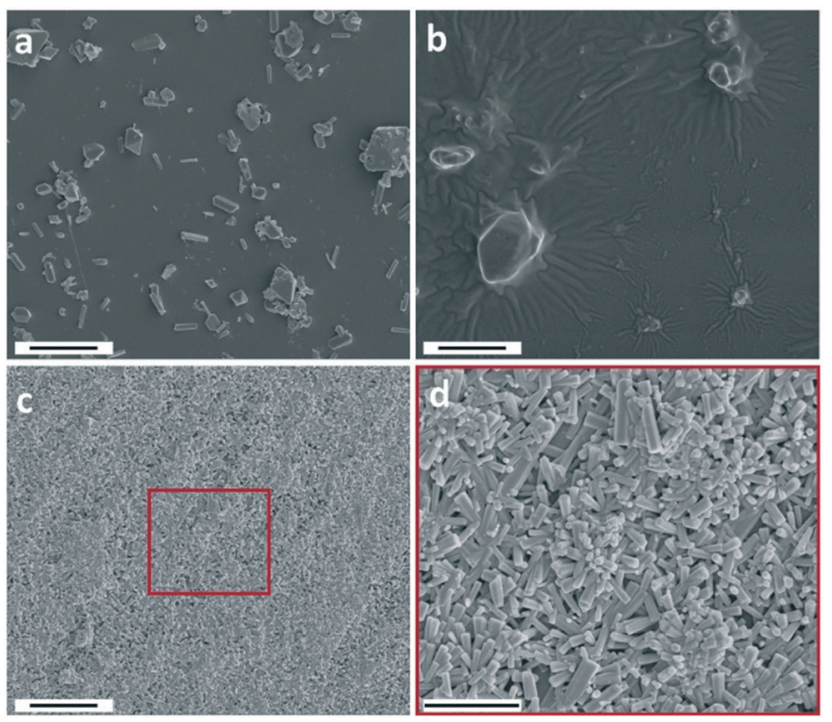

Fig. 5 SEM images of the $\mathrm{Zn}\left(\mathrm{NO}_{3}\right)_{2}$ reaction product on glass plates at $15 \mathrm{~min}(\mathrm{a}), 45 \mathrm{~min}$ (b) and $180 \mathrm{~min}$ (c and d). Scale bars are $5 \mu \mathrm{m}(\mathrm{a}-\mathrm{c})$ and $3 \mu \mathrm{m}$ (d). A lower magnification image of (b) is shown in Fig. S10 $\dagger$

(Fig. 5a). The diameter of the particles significantly increased with reaction time (30-45 min, Fig. $5 \mathrm{~b}$ and S10 $\dagger$ ), showing that the inserted hydroxide in the reaction is consumed by the formation of crystal growth on the glass surface. Many of these crystals have a rhombic shape, which is an atypical shape for both ZnO and LZHS, but it excellently matches with wulfingite zinc hydroxide as observed by McBride et al. ${ }^{6}$ The absence of LZHS species under mild condition is not unique as McPeak et $a .^{7}$ also showed a zinc hydroxide intermediary when using seeded $\mathrm{ZnO}$ growth from $\mathrm{Zn}\left(\mathrm{NO}_{3}\right)_{2}$. In the presence of $\mathrm{ZnAc}_{2}$ after $30 \mathrm{~min}$ reaction time no crystal growth can be observed by SEM on the glass surface (Fig. $\mathrm{S} 11 \dagger)$. After $180 \mathrm{~min}$ the surface was covered with $\mathrm{ZnO}$ pillar structures (Fig. 5c and d). These hexagonal pillars are significantly smaller than the initially observed crystals implying a transition via a dissolution-reprecipitation mechanism or their overgrowth with $\mathrm{ZnO}$ crystals as the reaction progresses. They also lack a preferred growing orientation which is due to the absence of an epitaxial seeding layer. ${ }^{37}$

Discrete SEM sampling experiments provided no reasonable evidence for the formation of LBZN as a precursor for the observed surface grown ZnO crystals. Liang et al. ${ }^{10}$ observed the initial formation of LBZN in dispersion by using a $24 \mathrm{~h}$ incubation period at RT. Therefore, to stimulate the formation of LBZN a similar $24 \mathrm{~h}$ incubation time was introduced. This resulted in a gradual reduction of the starting $\mathrm{pH}$ from roughly 6.8 to 6.5 yet yielding a clear solution (Fig. S12a †). Increasing this incubation time to several days results in the formation of a white precipitate. This matches with LBZN characteristics according to pXRD (Fig. $6 \mathrm{a}$ and $\mathrm{S} 12 \mathrm{~b} \dagger$ ), confirming its formation. Performing the reaction after $24 \mathrm{~h}$ incubation time a turbid dispersion was obtained (Fig. S13†). pH measurements (Fig. 6b) showed a
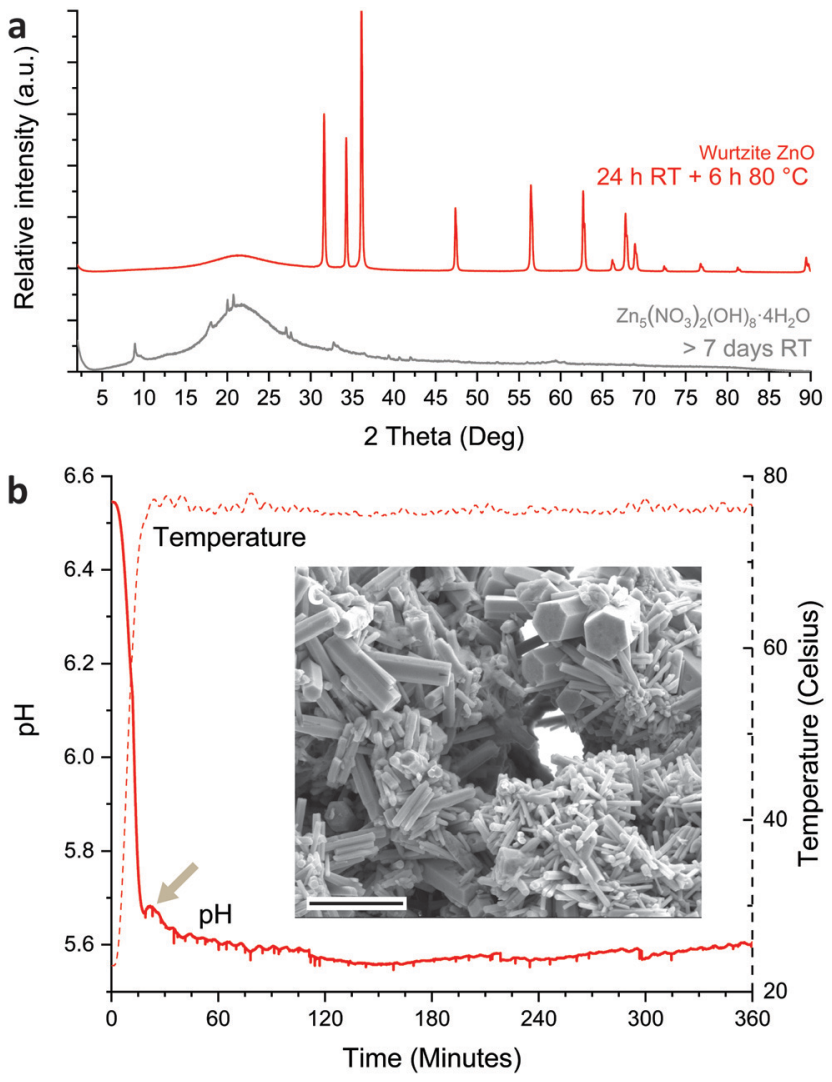

Fig. 6 LBZN obtained after $>7$ days incubated at RT and in-dispersion obtained $\mathrm{ZnO}$ form $\mathrm{Zn}\left(\mathrm{NO}_{3}\right)_{2}$ after introducing a $24 \mathrm{~h}$ waiting time: pXRD data (a), pH and temperature profile (b) SEM image (c) of the reaction product. The broad $\mathrm{PXRD}$ signals visible a about $20^{\circ}$ are from the substrate. Arrow indicates the second drop in $\mathrm{pH}$. SEM scale bar equals $2 \mu \mathrm{m}$.

second drop in $\mathrm{pH}$ at 25 min reaction time near the end of the typical initial $\mathrm{pH}$ drop. After purifying the dispersed product, pXRD and SEM (Fig. 6a and c) confirmed the formation of wurtzite $\mathrm{ZnO}$ in-dispersion. This shows that, for $\mathrm{Zn}\left(\mathrm{NO}_{3}\right)_{2}$ the preferred in-dispersion versus on-surface nucleation and growth of $\mathrm{ZnO}$ can be controlled by stimulating the formation of LBZN as a transient phase.

Considering the observations for all the studied zinc salts, when using $\mathrm{ZnAc}_{2}, \mathrm{ZnCl}_{2}$ or $\mathrm{ZnSO}_{4}$, LZHS crystals are rapidly formed under standard reaction conditions, however, only for $\mathrm{ZnAc}_{2}$ this LZHS phase transits into $\mathrm{ZnO}$ (Fig. 7a and b). Given the rapid formation of all three LZHS species their respective energy barriers are expected to be low and therefore a likely explanation for variation in evolution is the stability of these three transient phases. Although all three LZHS species can be transformed in $\mathrm{ZnO}$ under dry conditions by heating, this transition occurs for LBZA at 90 ${ }^{\circ} \mathrm{C},{ }^{32,33,38}$ whereas for LBZC $160{ }^{\circ} \mathrm{C}$ and LBZS $225{ }^{\circ} \mathrm{C}$ are required, implying their greater stability. ${ }^{29,30,39}$ Additionally, when $\mathrm{ZnO}$ is formed in the presence of LBZA, it does not directly result in the consumption of LBZA (Fig. 7b). As shown above, LBZA initially continues to mature in the presence of $\mathrm{ZnO}$, showing that $\mathrm{ZnO}$ is thermodynamically 
a

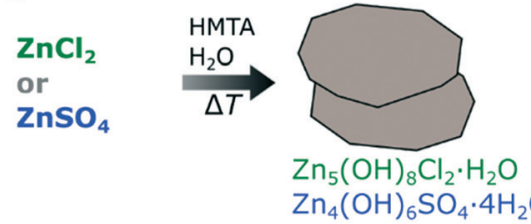

b

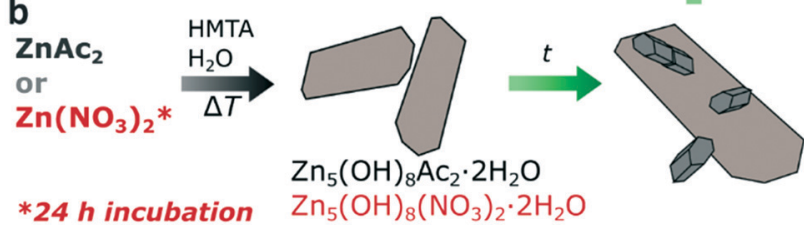

c....

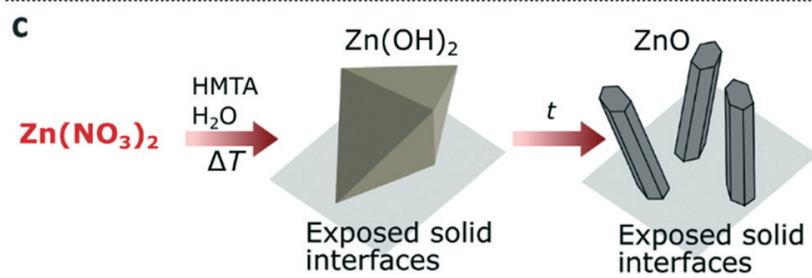

Fig. 7 Overview of the counter-ion dependent transition into $\mathrm{ZnO}$. The use of $\mathrm{ZnCl}_{2}$ or $\mathrm{ZnSO}_{4}$ results in the formation of stable LBZC or LBZS (a). For $\mathrm{ZnAC}_{2}$ or for $\mathrm{Zn}\left(\mathrm{NO}_{3}\right)_{2}$ after $24 \mathrm{~h}$ incubation time, LBZA or LBZN are formed which subsequently transform into $\mathrm{ZnO}$ in-dispersion (b). For $\mathrm{Zn}\left(\mathrm{NO}_{3}\right)_{2}$ under standard conditions $\mathrm{ZnO}$ is formed on exposed solid interfaces (on-surface) after the initial formation of zinc hydroxide (c).

stabile in the same range as LBZA. Given the higher stability of LBZC and LBZS precursors compared to LBZA, this could explain why these phases do not easily transform into $\mathrm{ZnO}$. This does not preclude that $\mathrm{ZnCl}_{2}$ and $\mathrm{ZnSO}_{4}$ can be used to form ZnO via a HMTA-mediated precipitation, as this has been achieved, ${ }^{5,23,25}$ but it does show that these systems will likely be more sensitive to specific reaction conditions and that their transition into $\mathrm{ZnO}$ might be less straightforward.

When using $\mathrm{Zn}\left(\mathrm{NO}_{3}\right)_{2}$, $\mathrm{ZnO}$ can be formed in-dispersion after the initial formation of LBZN, suggesting a similar mechanism as for the formation of $\mathrm{ZnO}$ from $\mathrm{ZnAc}_{2}$ (Fig. 7b). However, in the absence of an initial incubation period at RT, the formation of LBZN is limited compared to the heterogeneous nucleation and growth of zinc hydroxide on solid interfaces exposed to the reaction solution (Fig. 7c). This implies that either the energy barrier for LBZN nucleation is relatively high compared to the other LZHS or that the present nitrate molecules promote the formation of zinc hydroxide. Based on available data neither hypothesis can be excluded. In the absence of LBZN formation, hexagonal wurtzite $\mathrm{ZnO}$ pillars are still formed, but they are predominantly formed on surfaces present, resulting in a non-measurable quantity in the dispersion. A possible cause for this is the high concentration of zinc and hydroxide near the solid interfaces. As discussed previously, a more likely alternative is that both LBZN and LBZA play a role as ZnO nucleation template. This is supported by the similar shape, similar hexagonal spacings in the (001) plane of both species and that the main growth direction of the $\mathrm{ZnO}$ crystals is perpendicular to that of the LZHS sheets. The observed occurrence of $\mathrm{ZnO}$ nucleation in the presence of LBZA, when using $\mathrm{ZnAc}_{2}$, further supports this hypothesis.

\section{Conclusions}

We have shown that for the formation of $\mathrm{ZnO}$ in-dispersion, a LZHS transient phase is required. The stability of this transient phase, which depends on reaction chemistry and conditions, is an essential parameter to be considered. A too stable phase, as in the case of LBZC and LBZS, can prevent the transition of this transient phase into ZnO. For LBZA under the investigated reaction conditions, pure $\mathrm{ZnO}$ can be formed in-dispersion. Initially, LBZA is formed, followed by a gradual formation of $\mathrm{ZnO}$. During the initial formation of ZnO crystals, the LBZA crystals keep growing resulting in micrometer-sized rectangular sheets. These LBZA sheets then rapidly disintegrate (most likely by brittle fracture) resulting in an acceleration of $\mathrm{ZnO}$ growth. It is highly likely that the LBZA initially present acts as a nucleating template for the formation of $\mathrm{ZnO}$. For $\mathrm{Zn}\left(\mathrm{NO}_{3}\right)_{2}$ initial formation or suppression of LBZN can be stimulated (aging), resulting either in $\mathrm{ZnO}$ dominantly formed as dispersed particles or particles on-surfaces. This not only implies that there are multiple paths for the formation of $\mathrm{ZnO}$ under mild reaction conditions, it also shows that the counter-ion has a strong effect on the formation and stability of the transient phases, in turn influencing the final reaction product and its nucleation location.

\section{Funding sources}

This project received funding by a TopPunt grant (Bi-Hy, 718.016.003) of the Netherlands Organization for Scientific Research (NWO).

\section{Conflicts of interest}

There are no conflicts to declare.

\section{Acknowledgements}

The authors would like to thank Prof. Nico A. J. M. Sommerdijk (Radboud UMC, Nijmegen) for the scientific discussions during the early stages of this work.

\section{Notes and references}

1 J. J. De Yoreo, P. U. P. A. Gilbert, N. A. J. M. Sommerdijk, R. L. Penn, S. Whitelam, D. Joester, H. Z. Zhang, J. D. Rimer, A. Navrotsky, J. F. Banfield, A. F. Wallace, F. M. Michel, F. C. Meldrum, H. Colfen and P. M. Dove, Science, 2015, 349, aaa6760.

2 G. Mirabello, A. Keizer, P. H. H. Bomans, A. Kovacs, R. E. Dunin-Borkowsk, N. A. J. M. Sommerdijk and H. Friedrich, Chem. Mater., 2019, 31, 7320-7328. 
3 W. J. E. M. Habraken, J. H. Tao, L. J. Brylka, H. Friedrich, L. Bertinetti, A. S. Schenk, A. Verch, V. Dmitrovic, P. H. H. Bomans, P. M. Frederik, J. Laven, P. van der Schoot, B. Aichmayer, G. de With, J. J. DeYoreo and N. A. J. M. Sommerdijk, Nat. Commun., 2013, 4, 12.

4 Y. F. Xu, K. C. H. Tijssen, P. H. H. Bomans, A. Akiva, H. Friedrich, A. P. M. Kentgens and N. A. J. M. Sommerdijk, Nat. Commun., 2018, 9, 1507.

5 K. Govender, D. S. Boyle, P. B. Kenway and P. O'Brien, J. Mater. Chem., 2004, 14, 2575-2591.

6 R. A. McBride, J. M. Kelly and D. E. McCormack, J. Mater. Chem., 2003, 13, 1196-1201.

7 K. M. McPeak, M. A. Becker, N. G. Britton, H. Majidi, B. A. Bunker and J. B. Baxter, Chem. Mater., 2010, 22, 6162-6170.

8 N. J. Nicholas, G. V. Franks and W. A. Ducker, CrystEngComm, 2012, 14, 1232-1240.

9 W. L. Feng, B. C. Wang, P. Huang, X. D. Wang, J. Yu and C. W. Wang, Mater. Sci. Semicond. Process., 2016, 41, 462-469.

10 M. K. Liang, M. J. Limo, A. Sola-Rabada, M. J. Roe and C. C. Perry, Chem. Mater., 2014, 26, 4119-4129.

11 B. Song, X. Cui, Y. Q. Wang, L. F. Si, Z. X. Kou, W. W. Tian, C. Yi and Y. M. Sun, Cryst. Growth Des., 2016, 16, 4877-4885.

12 J. Lee, A. J. Easteal, U. Pal and D. Bhattacharyya, Curr. Appl. Phys., 2009, 9, 792-796.

13 E. S. Jang, J. H. Won, Y. W. Kim, Z. Cheng and J. H. Choy, CrystEngComm, 2011, 13, 546-552.

14 T. H. Hsieh, J. Y. Chen, C. W. Huang and W. W. Wu, Chem. Mater., 2016, 28, 4507-4511.

15 S. Yin and T. Sato, J. Mater. Chem., 2005, 15, 4584-4587.

16 J. G. Strom and H. W. Jun, J. Pharm. Sci., 1980, 69, 1261-1263.

17 R. Devaraj, K. Venkatachalam, K. Saravanakumar, P. M. Razad and K. Mahalakshmi, J. Mater. Sci.: Mater. Electron., 2016, 27, 12201-12208.

18 G. Amin, M. H. Asif, A. Zainelabdin, S. Zaman, O. Nur and M. Willander, J. Nanomater., 2011, 2011, 1-9.

19 K. M. McPeak, T. P. Le, N. G. Britton, Z. S. Nickolov, Y. A. Elabd and J. B. Baxter, Langmuir, 2011, 27, 3672-3677.

20 R. Parize, J. Garnier, O. Chaix-Pluchery, C. Verrier, E. Appert and V. Consonni, J. Phys. Chem. C, 2016, 120, 5242-5250.

21 Y. Liu, K. P. Tai and S. J. Dillon, Chem. Mater., 2013, 25, 2927-2933.
22 S. E. R. Tay, A. E. Goode, J. N. Weker, A. A. Cruickshank, S. Heutz, A. E. Porter, M. P. Ryan and M. F. Toney, Nanoscale, 2016, 8, 1849-1853.

23 P. M. Perillo, M. N. Atia and D. F. Rodriguez, Matéria (Rio J.), 2018, 23(2), e12133.

24 T. F. Long, S. Yin, K. Takabatake, P. Zhnag and T. Sato, Nanoscale Res. Lett., 2009, 4, 247-253.

25 M. R. Alenezi, S. J. Henley, N. G. Emerson and S. R. P. Silva, Nanoscale, 2014, 6, 235-247.

26 M. R. Alenezi, A. S. Alshammari, K. D. G. I. Jayawardena, M. J. Beliatis, S. J. Henley and S. R. P. Silva, J. Phys. Chem. C, 2013, 117, 17850-17858.

27 C. T. Sun and D. F. Xue, CrystEngComm, 2016, 18, 1262-1272.

28 C. Ou, P. E. Sanchez-Jimenez, A. Datta, F. L. Boughey, R. A. Whiter, S. L. Sahonta and S. Kar-Narayan, ACS Appl. Mater. Interfaces, 2016, 8, 13678-13683.

29 A. Moezzi, M. B. Cortie and A. M. McDonagh, Dalton Trans., 2013, 42, 14432-14437.

30 A. Moezzi, M. Cortie and A. McDonagh, Dalton Trans., 2016, 45, 7385-7390.

31 Q. J. Yu, W. Y. Fu, C. L. Yu, H. B. Yang, R. H. Wei, M. H. Li, S. K. Liu, Y. M. Sui, Z. L. Liu, M. X. Yuan, G. T. Zou, G. R. Wang, C. L. Shao and Y. C. Liu, J. Phys. Chem. C, 2007, 111, 17521-17526.

32 M. S. Yao, P. Hu, N. Han, F. Ding, C. L. Yin, F. L. Yuan, J. Yang and Y. F. Chen, Sens. Actuators, B, 2013, 186, 614-621.

33 Q. Y. Cui, K. Yu, N. Zhang and Z. Q. Zhu, Appl. Surf. Sci., 2008, 254, 3517-3521.

34 M. N. R. Ashfold, R. P. Doherty, N. G. Ndifor-Angwafor, D. J. Riley and Y. Sun, Thin Solid Films, 2007, 515, 8679-8683.

35 H. J. Gao, B. H. Ji, I. L. Jager, E. Arzt and P. Fratzl, Proc. Natl. Acad. Sci. U. S. A., 2003, 100, 5597-5600.

36 X. Zhang, A. Vyatskikh, H. J. Gao, J. R. Greer and X. Y. Li, Proc. Natl. Acad. Sci. U. S. A., 2019, 116, 6665-6672.

37 J. H. Kim, E. M. Kim, D. Andeen, D. Thomson, S. P. DenBaars and F. F. Lange, Adv. Funct. Mater., 2007, 17, 463-471.

38 A. Moezzi, A. McDonagh, A. Dowd and M. Cortie, Inorg. Chem., 2013, 52, 95-102.

39 W. X. Zhang and K. Yanagisawa, Chem. Mater., 2007, 19, 2329-2334. 